Working in mental health settings is a growing area of practice for occupational therapists. The work nowadays is mostly within the community, where occupational therapists may be found in a wide variety of teams. This study investigated the specific challenges that new graduate occupational therapists are faced with when commencing work in a mental health setting.

One-to-one semi-structured interviews were carried out with 15 newly graduated occupational therapists, working in mental health settings in south-east Queensland. The interview transcripts were analysed using a consensual qualitative research approach.

Three domains were identified from the transcripts. The first related to the ideas of the participants about the skills and knowledge needed by new graduates commencing mental health practice; the second related to the extent to which undergraduate studies had prepared them for practice; and the third related to the means by which they acquired capacity to practise and overcame deficits in skills and knowledge. The core ideas and themes associated with these domains are examined and the implications of the findings for education and training and for orientation to practice are discussed.

\title{
The Challenge of Working in Mental Health Settings: Perceptions of Newly Graduated Occupational Therapists
}

\author{
Chris Lloyd, ${ }^{1}$ Robert King ${ }^{1}$ and Liz Ryan ${ }^{1}$
}

\section{Introduction}

Previous literature has explored the period of professional growth and development experienced by newly graduated occupational therapists in a range of practice areas; however, there is little research specific to mental health. Recent studies have uncovered the challenging nature of work in the area of mental health for all occupational therapists (Lloyd et al 2002, 2005, Duffy and Nolan 2005). The issues that newly graduated occupational therapists find challenging, along with the strategies that they use to meet these challenges, have not been addressed specifically. In this study, qualitative research data drawn from audio-recorded interviews were used to explore the challenges that newly graduated occupational therapists

\footnotetext{
${ }^{1}$ The University of Queensland, Australia.

Corresponding author: Dr Chris Lloyd, Senior Lecturer, Division of Occupational Therapy, University of Queensland, Q 4072, St Lucia, Australia. Email: Iloyd@onthenet.com.au
}

Submitted: 10 November 2006.

Accepted: 22 October 2007

Key words: New graduates, mental health.

Reference: Lloyd C, King R, Ryan L (2007) The challenge of working in mental health settings: perceptions of newly graduated occupational therapists. British Journal of Occupational Therapy, 70(11), 460-470. are faced with when commencing work in a mental health setting. The data were also used to explore the specific coping strategies utilised to overcome these challenges.

The following review of the literature explores the roles and responsibilities of occupational therapists working in mental health settings, along with the experiences and needs of newly graduated occupational therapists working in general occupational therapy practice settings.

\section{Literature review}

\section{Occupational therapists' roles in mental health settings}

The changing structure of mental health service provision influenced by the National Mental Health Plan (Australian Health Ministers 1992), the Second National Mental Health Plan (Australian Health Ministers 1998), the Third National Mental Health Plan (Australian Health Ministers 2003) and the National Standards for Mental Health Services (Australian Health Ministers 1996) has meant that the expectations placed on occupational therapists working within mental health settings have become ambiguous. Their role is often blurred with the roles carried out by other members of the interdisciplinary team (Yau 1995, Paul 1996, Lloyd et al 2002). 
The transition from institutionalised settings to community settings has resulted in occupational therapists working more autonomously than previously (Harries 1998). It has increased the requirements for occupational therapists to utilise the generic mental health skills involved in case management roles. Regardless of professional training, all team members undertake similar types of work (Greaves et al 2002). This has limited the opportunities that occupational therapists have to make use of discipline-specific skills (Lloyd et al 2002); for example, occupational therapy discipline-specific assessments. Working in the community requires different skills from those required for working in an inpatient unit because it involves a high level of responsibility and the carrying out of generic skills, such as medication monitoring, mental state examinations and risk assessments.

Research based on the Mental Health Workers Core Competencies Scale has shown that occupational therapists have a high level of self-perceived competence in professional tasks when compared with other health professionals working in mental health (Greaves et al 2002). This, in particular, related to multidisciplinary teamwork and human relation skills and being able to expand their skill base to include generic tasks, such as triage and case management.

The most commonly performed work activities of occupational therapists working in mental health have been identified in several recent studies (Craik et al 1998, Lloyd et al 2002, 2003, 2004, Duffy and Nolan 2005). Craik et al (1998) conducted a survey of 137 occupational therapists working in mental health in the United Kingdom. They found that occupational therapists' interventions focused on leisure, counselling, anxiety management, activities of daily living and creative activities. It was also found that occupational therapists were engaged in a range of non-discipline-specific tasks, such as counselling, medication and being on-call. In a survey of 63 occupational therapists working in inpatient settings (Duffy and Nolan 2005), the skills cited by participants were divided into generic and profession-specific. The generic skills involved communication skills, flexibility and adaptability, assessment skills and group work skills. The discipline-specific skills included using occupational performance in the workplace, assessments with an emphasis on functional skills, using activity to structure time and the grading of activities.

Lloyd et al (2002) conducted a survey of 148 Australian occupational therapists working in mental health settings. The areas of practice carried out by occupational therapists included generic clinical, specialist rehabilitation, group work and service planning. A later study carried out by Lloyd et al (2004) of 196 occupational therapists found that the most commonly performed generic clinical work involved psychosocial assessment, links with community resources, mental state examinations and supportive counselling. Specialist work activities were assessing occupational performance, living skills training, the use of activities and conducting functional assessments. In
New Zealand, Lloyd et al (2003) conducted a cross-sectional survey of 156 occupational therapists. The participants spent a greater percentage of time in continuing care than in acute services. Their work activities were predominantly general clinical (symptom monitoring, specialist counselling and linkages to community resources). Specialist clinical work activities included the use of activities, occupational performance and activities of daily living.

Based on the above studies, the generic and specific skills are outlined in Table 1. These studies show that occupational therapists are expected to draw from a broad range of skills, several of which may not be emphasised in occupational therapy education and training. The extent to which new graduates are prepared with these skills has not been addressed in previous studies.

Table 1. Generic versus occupational therapy specific skills used in a mental health setting

\begin{tabular}{|c|c|}
\hline Generic skills & Discipline-specific skills \\
\hline $\begin{array}{l}\text { - Case management } \\
\text { - Symptom monitoring } \\
\text { - Crisis management } \\
\text { - Supportive counselling } \\
\text { - Psychosocial assessments } \\
\text { - Linking clients with community } \\
\text { resources } \\
\text { - Mental state examinations } \\
\text { - Home visits } \\
\text { - Liaison with support networks } \\
\text { - Communication with clients } \\
\text { - Communication with the } \\
\text { interdisciplinary team } \\
\text { - Flexibility } \\
\text { - Adaptability } \\
\text { - Assessment skills } \\
\text { - Group work skills } \\
\text { - Patience } \\
\text { - Empathy } \\
\text { - Sense of humour }\end{array}$ & $\begin{array}{l}\text { - Use of activities with clients } \\
\text { - Utilising occupational } \\
\text { performance in the workplace } \\
\text { - Utilising assessments } \\
\text { - Developing appropriate } \\
\text { interventions } \\
\text { - Performing activity analyses } \\
\text { - Developing independence as } \\
\text { an occupational therapist } \\
\text { - Making use of graded activities } \\
\text { to structure a client's time }\end{array}$ \\
\hline
\end{tabular}

\section{Experiences of newly graduated occupational therapists}

A qualitative study of occupational therapy students from Australia and the United States conducted by Lyons (1995) reported that fieldwork placements (now practice placement education) in community mental health settings were essential in preparing a new graduate to work in this sector. The fieldwork experience appeared to enrich participants' insights into the lives and needs of people with mental illness. Craik and Austin (2000) conducted a study aiming to identify how British occupational therapists felt that their undergraduate education and training prepared them to work in mental health settings. Out of 137 participants, $37 \%$ felt that they were well prepared, $44 \%$ felt that they were partly prepared, and $19 \%$ reported 
that they had had insufficient training to work in mental health. Those who felt that it was not sufficient highlighted that their pre-registration education was too theoretical and not practical enough, with too few fieldwork placements. They also commented on the lack of training in specific assessment techniques and the subsequent problems of coping with the realities of practice.

Many new graduates experience problems in adjusting to their first occupational therapy position. A Scottish study conducted by Parker (1991) found that new graduates identified the major sources of apprehension as making decisions, a lack of practical experience and a lack of theoretical knowledge. She suggested that the general needs of newly qualified occupational therapists included supervision from a key person in their department, regular contact with other newly graduated occupational therapists, a comprehensive orientation to their new role and sustained contact with their educational institution.

Tryssenaar (1999) described the lived experience of becoming an occupational therapist. Three broad themes were identified: through rose-coloured glasses, the impact of reality, and onward and upward. The therapist was grateful to be employed, but soon found that everything became a challenge. She grounded herself in client-centred practice and started to think about the future and making changes in her approach. A later qualitative study conducted by Tryssenaar and Perkins (2001) examined the reflective journals kept by occupational therapy and physical therapy participants. This covered the period of their final fieldwork placement and the first year of practice. The themes that were identified included four consecutive stages of transition: euphoria and angst, reality of practice and adaptation. They concluded that recognising the stages in the process of transition from student to therapist may assist in educational curriculum development and in clinical support and supervision for new graduates. The importance of educators making education relevant to practice, while maintaining a theoretical perspective, was highlighted.

An Australian study conducted by Hummell and Koelmeyer (1999) found a number of factors that would have assisted the transition within the workplace. These included having more support and supervision, increased knowledge and skills, and a strong professional identity. These studies were generalised to all fields of clinical practice and, although relevant to all occupational therapists, do not discuss specifically the challenges, or methods of overcoming the challenges, experienced by new graduates working in mental health.

The initial professional experience of a newly graduated occupational therapist can influence his or her clinical performance, and retention in or withdrawal from occupational therapy practice, such as the degree of support in the workplace, the level of supervision and the workload (Rugg 1999, Lee and Mackenzie 2003). It has been well documented that there is difficulty in recruiting and retaining health professionals, especially occupational therapists in a mental health setting (Sutton and Griffin
2000). New graduates are often given increased responsibility and challenging caseloads before they have adequate confidence and experience in the profession (Wolfenden et al 1996, Onyett et al 1997, Hunter and Nicol 2002). Lloyd et al (2005) reported that occupational therapists working in mental health perceived their job environments to be highly pressured. The participants in their study reported that they experienced high levels of stress attributable to the work environment, with factors such as a lack of resources, high workloads, difficult professional relationships, a difficult clientele and professional self-doubt, which had an impact on their experience in the mental health setting.

The commonly defined challenges of commencing work as an occupational therapist include the development of self-confidence and decision-making skills; the application of theoretical knowledge; developing clinical skills; time management; communicating with other health professionals; the development of a professional identity; working as part of a team; promoting the occupational therapy role; making use of limited resources; physically attending work each day; identifying and making use of supports and mentors; and working without direct supervision (Parker 1991, Paul 1996, Wolfenden et al 1996, Atkinson and Steward 1997, Hummell and Koelmeyer 1999, Lloyd et al 2002, Duffy and Nolan 2005). A Canadian study conducted by Krupa and Clark (1995) identified the key expectations of an occupational therapist working in a case management role. They implied that new graduates may not be formally trained to carry out tasks such as crisis management, health education and counselling. New graduates must, therefore, develop these skills through on-site resources and support, hands-on training and formal postgraduate education.

It is only by gaining an understanding of the specific challenges faced by occupational therapists when they commence working in mental health that it is possible to inform curriculum development. Therefore, this study investigated the specific challenges that new graduate occupational therapists experienced.

\section{Method}

\section{Overview}

This was a qualitative study using the consensual qualitative research (CQR) approach (Hill et al 1997, 2005). The main elements in CQR are the use of open-ended questions in semi-structured data-collection techniques, which allows for the collection of consistent data across individuals as well as a more in-depth examination of individual experiences; several judges throughout the data analysis process to foster multiple perspectives; a consensus to arrive at a judgement about the meaning of the data; at least one auditor to check the work of the primary team; and domains, core ideas and cross-analysis in the data analysis (Hill et al 1997, 2005). 


\section{Participants}

A sample of 15 participants (one male, 14 female) was recruited for the study. This is consistent with the sample size recommended by Hill et al $(1997,2005)$ as being necessary to ensure validity in studies of this design. All participants were within their first 2 years of practice after graduating from an occupational therapy course at the University of Queensland, James Cook University or Dunedin Polytechnic, New Zealand. At the time of the interview, all participants were working in a government mental health setting (eight inpatient settings and seven community settings) in south-east Queensland. Table 2 summarises the key demographic characteristics of the participants.

\section{Procedure}

Ethical approval was obtained from the University of Queensland Ethics Committee. A list of all occupational therapists working in south-east Queensland was obtained
Table 2. Demographics of participants

\begin{tabular}{|c|c|c|}
\hline & $\begin{array}{l}\text { ge Gender } \\
\text { ears) }\end{array}$ & \\
\hline \multicolumn{3}{|c|}{ _........................Female........4 months.......Regi } \\
\hline \multicolumn{3}{|c|}{.........23 ......Female.......2 months......Metropolitan community.... } \\
\hline \multicolumn{3}{|c|}{ 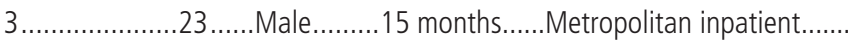 } \\
\hline \multicolumn{3}{|c|}{$\ldots \ldots \ldots \ldots \ldots . . .42 \ldots . .$. Female $\ldots \ldots . . .5$ months.......Metropolitan inpatient...... } \\
\hline \multicolumn{3}{|c|}{$\ldots \ldots \ldots \ldots \ldots \ldots .23 \ldots . . .$. Female $\ldots \ldots . . . .4$ months.......Metropolitan community.. } \\
\hline \multicolumn{3}{|c|}{ 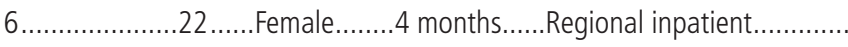 } \\
\hline \multicolumn{3}{|c|}{ 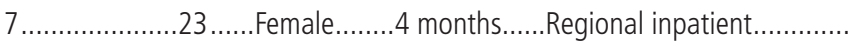 } \\
\hline \multicolumn{3}{|c|}{......24 ......Female......17 months.... } \\
\hline \multicolumn{3}{|c|}{........22 22....Female.......2 months.......Regional co } \\
\hline \multicolumn{3}{|c|}{ 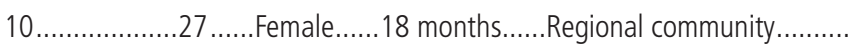 } \\
\hline \multicolumn{3}{|c|}{ 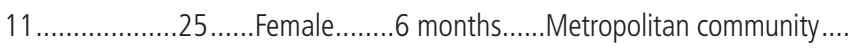 } \\
\hline \multicolumn{3}{|c|}{ 2_......................Female.....16 months......Metropolitan inpatient...... } \\
\hline \multicolumn{3}{|c|}{ 3 .......................Female........5 months......Metropolitan community ... } \\
\hline \multicolumn{3}{|c|}{$4 \ldots \ldots \ldots \ldots \ldots \ldots . .22 \ldots . . . . F e m a l e \ldots \ldots . . .3$ months.......Metropolitan inpatient....... } \\
\hline & & \\
\hline
\end{tabular}

U: Unweighted value refers to the total number of transcripts in which the theme was mentioned.

W: Weighted value refers to the total number of instances (including multiple instances within a single transcript) of the themes across all transcripts.

These values are displayed in Tables 3-5.

Table 3. Domain 1: Skills and knowledge that new graduate occupational therapists need to work in mental health

\begin{tabular}{|c|c|c|c|}
\hline Themes & W & $\mathbf{U}$ & Illustrative quotes \\
\hline \multicolumn{4}{|c|}{ Core idea 1: Discipline-specific skills } \\
\hline $\begin{array}{l}\text { Selecting and interpreting } \\
\text { occupational therapy assessments }\end{array}$ & 56 & 15 & $\begin{array}{l}\text { 'There's lots of assessments here that I haven't used like the DACSA, so just trying to organise } \\
\text { relevant assessments and learn new ones.' (Transcript 5.) }\end{array}$ \\
\hline Using clinical reasoning to develop & 54 & 15 & 'The most challenging was the clinical reasoning, just making those judgements.' (Transcript 8.) \\
\hline
\end{tabular}

interventions

Knowledge of occupational therapy

$49 \quad 15$

role in mental health

Utilising discipline-specific skills in a generic or case management role

\section{Core idea 2: Generic skills}

Counselling and psychoeducation

Generic assessments

$42 \quad 13$

Client management

Knowledge of mental illnesses and medications
'Just looking a bit more about what the OT role can be in mental health, and how you maintain your identity as an OT when you're working in mental health, because a lot of its really generic.' (Transcript 8.)

1 'So I'll get clients who have really OT specific needs in addition to their other complex needs relating to medication.' (Transcript 11.)

'I think a good knowledge of the common interventions used in mental health ... at the moment I'm using a lot of CBT and psychoeducation, so it is important to know what you are doing and be confident in what you are doing.' (Transcript 5.)

'Essential skills are how to work in a team, mental state, risk assessments, medication, Mental Health Act, and how to utilise the Recovery Model.' (Transcript 5.)

'The main challenge is being responsible for your clients, in case management there is quite a lot of responsibility with clients.' (Transcript 13.)

'Medication is a big challenge. I never realised how much emphasis there was on it in case management ... what drugs there are, what dosage they come on, what are the side effects.' (Transcript 2.)

'I don't really think case management is much of a generic role. I always find opportunities with my clients to do occupational therapy specific stuff, assessing mental state and things like that become secondary.' (Transcript 13.)

'Really good knowledge of the Mental Health Act, feeling confident about conducting mental state exams and realising it is not just a checklist.' (Transcript 4.)

'Getting hold of policies and procedures within the workplace and in mental health the policies and procedures are a bit more detailed because you are working with people who have particular legal issues, like they are under involuntary treatment orders or mental health courts.' (Transcript 3.) 


\begin{tabular}{|c|c|c|c|}
\hline Themes & W & $\mathbf{U}$ & Illustrative quotes \\
\hline \multicolumn{4}{|c|}{ Core idea 3: Personal attributes } \\
\hline $\begin{array}{l}\text { Good communication and } \\
\text { interpersonal skills }\end{array}$ & 58 & 15 & $\begin{array}{l}\text { 'I think communication skills, counselling skills, empathic listening and reflective practice and all } \\
\text { those things that are really important in building rapport with your clients.' (Transcript 13.) }\end{array}$ \\
\hline Confidence and assertiveness & 45 & 14 & $\begin{array}{l}\text { 'Probably when you are a new grad and you are working in a team just being assertive and } \\
\text { confident enough to say "oh I think that would be really good".' (Transcript 6.) }\end{array}$ \\
\hline Organisational skills & 37 & 14 & $\begin{array}{l}\text { 'Time management for the first few weeks is just sussing out how many people I can fit in a day, } \\
\text { what I can work and manage in time to get notes and all the paperwork done, so now I've } \\
\text { sussed that out I can work out how much I can do in a day.' (Transcript 2.) }\end{array}$ \\
\hline Stress management & 31 & 13 & $\begin{array}{l}\text { 'I started suffering from anxiety and panic attacks so I decided to use public transport and use the } \\
\text { time to read something relaxing or professional literature, and that also involved walking to and } \\
\text { from the station, then I joined the gym and that all improved the balance in my life.' (Transcript 10.) }\end{array}$ \\
\hline Ability to work autonomously & 23 & 12 & $\begin{array}{l}\text { 'In a hospital there are always staff around you, but in a community setting you are pretty } \\
\text { much on your own because people are always out and people leave at different times, there } \\
\text { is a general lack of debriefing with peers, and they don't generally have a lunch break as well.' } \\
\text { (Transcript 10.) }\end{array}$ \\
\hline $\begin{array}{l}\text { Knowledge of own values } \\
\text { and abilities }\end{array}$ & 23 & 10 & $\begin{array}{l}\text { 'Essentially you just need to know your limits as an OT, know exactly what occupational therapy } \\
\text { can bring to the mental health arena, know specifically what you are looking for when you are } \\
\text { trying to assist people.' (Transcript 3.) }\end{array}$ \\
\hline Flexibility & 15 & 10 & $\begin{array}{l}\text { 'I think you have to be very flexible, especially when there are people who fluctuate a lot, } \\
\text { because you can go and do all this work for a consumer, and then they won't engage, you need } \\
\text { to be able to adapt all the time and think really, really quickly on your feet.' (Transcript 12.) }\end{array}$ \\
\hline
\end{tabular}

from the 'Who's working where' section on the OT Australia website, which identified services with mental health components (it must be noted that not all occupational therapists are members of OT Australia). Twenty-one centres were contacted via telephone to determine whether there were occupational therapists working in the setting with less than 2 years' experience. A total of 18 occupational therapists were contacted and, of these, 15 agreed to participate in the study. An information letter outlining the study in more detail was sent to all participants, followed by a phone call to confirm their involvement and to arrange a time to conduct the audio-taped interview.

The participants were not given the interview schedule ahead of time. The interviews were of a semi-structured and mostly open-ended nature, as recommended by Hill et al (1997). The questions used to guide the interviews are given in Appendix 1. The interviews lasted approximately one hour and were conducted on a one-to-one, face-to-face basis, and recorded using a standard tape recorder. The audio recordings were transcribed by the interviewer and sent back to the participants to present the opportunity for additions, corrections or clarification of their responses. Fourteen out of the 15 transcripts were returned with minor changes.

\section{Data analysis}

\section{Developing domains}

One member of the research team conducted an initial review of the transcripts and compiled a list of provisional domains.
Domains are used to cluster information about similar topics (Hill et al 1997). The initial domains were in part theoretically derived (based on a review of the literature) and in part based on material in the transcripts. Three team members then met to review a sub-sample of the transcripts so as to test the validity of the provisional domains. Following this review, the team reached a consensual decision as to the final domains to be used in the analysis.

\section{Constructing core ideas}

Each primary team member read each transcript independently and organised the raw data in each domain into core ideas (Hill et al 1997). This process aims to capture the essence of what the interviewee has said, using fewer words and with more clarity. Once the team members had developed the core ideas independently, they came together as a team to discuss the ideas until a consensus was reached.

\section{Cross-analysis}

The core ideas from each transcript were collated by one researcher to identify common and unique themes throughout the transcripts. Common themes were classified as general (present in all or all but one transcript), typical (present in more than half the transcripts) or variant (present in at least two transcripts but in less than half the transcripts) (Hill et al 1997).

\section{Auditing}

The auditor's role was to check whether the raw material was in the correct domain, that all important material had 
been represented in the core ideas, that the wording of the core ideas captured the essence of the raw data, and that the cross-analysis represented the data (Hill et al 1997). The auditor provided detailed feedback at each stage of the analysis process.

\section{Stability check}

The stability checking procedures recommended by Hill et al (1997) were followed after the initial cross-checking process was complete. Stability checking involves the analysis of a subset of transcripts (in this case three), which are withheld from the initial cross-analysis so as to determine whether new domains, categories or relationships between the subgroups can be identified or whether the existing domains and categories are stable. Since the analysis of the remaining participant data did not reveal new domains or categories, the findings were considered to be stable.

\section{Results}

Three key domains were identified when using the CQR procedure described above: skills and knowledge; preparation for practice; and achieving competence. These domains, together with the core ideas, principal

U: Unweighted value refers to the total number of transcripts in which the theme was mentioned.

W: Weighted value refers to the total number of instances (including multiple instances within a single transcript) of the themes across all transcripts.

Table 4. Domain 2: New graduates' preparation for practice in mental health

\begin{tabular}{|c|c|c|c|}
\hline Themes & W & $\mathbf{U}$ & Illustrative quotes \\
\hline \multicolumn{4}{|c|}{ Core idea 1: Skills and knowledge that the participants were well equipped with } \\
\hline Skills developed on prac & 29 & 5 & $\begin{array}{l}\text { 'If I hadn't done the prac that I'd done, I would not have been able to do a mental health job. I just } \\
\text { don't think I would have had the skills to do it.' (Transcript 8.) }\end{array}$ \\
\hline $\begin{array}{l}\text { Knowledge of occupational } \\
\text { therapy frameworks }\end{array}$ & 20 & 12 & $\begin{array}{l}\text { 'I think you graduate with all the basic skills to tackle things from an OT perspective and I think } \\
\text { you just have to take it upon yourself to do more professional development to stay on top of it.' } \\
\text { (Transcript 3.) }\end{array}$ \\
\hline
\end{tabular}

\section{Core idea 2: Skills and knowledge that the participants needed to develop further}

Knowledge of the occupational

therapy role

Developing interventions

based on occupational

therapy frameworks

$42 \quad 13$

Client management and

boundary setting

Confidence and assertiveness

$35 \quad 12$

Selecting and interpreting

occupational therapy

assessments

Legislation

$30 \quad 14$

Medication and diagnoses

knowledge

$28 \quad 12$

Organisational skills
'When I first came here it took two or three weeks to work out what I was actually supposed to be doing in my role as the OT in such a massive organisation, and that I think is a big challenge for a lot of people.' (Transcript 11.)

3 'I think that if you're working in occupational therapy and you're working in mental health you need to know more on what programs ... what interventions you might try on someone ... just having a repertoire of strategies and interventions you can offer to clients is a really big thing. In particular, if a client says "I can't sleep, I can't do anything, I don't want to have a shower ..." dealing with relapse management when the client doesn't acknowledge that there's anything wrong with them ... so strategies and interventions you can actually use ...' (Transcript 4.)

3 'The boundary setting is huge, and it can't be taught to you at a university level what's going to work and what's not - that's a big challenge.' (Transcript 11.)

'I think it's just being a new grad and in a new position, I did find it difficult to step out there and say "hey I'm doing this listen to me".' (Transcript 14.)

$31 \quad 11$ 'There's a real lack of standardised assessments for mental health ... I've found that a bit of a struggle, but I'm slowly working it out ... it's hard not having supervision for that sort of thing ... it's just been challenging sourcing the assessments and knowing the appropriate one to use.' (Transcript 14.)

'It's been hard getting my head around what it means to be on an ITO, the mental health review tribunal, treatment plans and conditions of leave, and all that sort of stuff.' (Transcript 15.)

'You learn all this stuff at uni that they teach you, but actually seeing it in the real world rather than just reading in a text book - you just don't realise all the extra problems that go with mental health ... medication is a big challenge for me as well, I never realised how much emphasis there was on it in case management.' (Transcript 2.)

'Depending on which workplace you go to there are different expectations, levels of intensity in work pace in different areas that you work in and it can be little bit difficult to judge what you're going to get done in a day. It's a matter of learning how long things will take ... expecting that something will go wrong every day so you just accept that what your plan is for the day probably won't happen and you just work around it.' (Transcript 3.) 


\begin{tabular}{|c|c|c|c|}
\hline Themes & W & $\mathbf{U}$ & Illustrative quotes \\
\hline \multicolumn{4}{|c|}{ Core idea 3: Unexpected challenges that the participants experienced when commencing work } \\
\hline Lack of professional identity & 41 & 13 & $\begin{array}{l}\text { 'The nurses sort of expected me to entertain clients and play games with them and do activities ...' } \\
\text { (Transcript 14.) }\end{array}$ \\
\hline $\begin{array}{l}\text { Lack of knowledge and } \\
\text { experience }\end{array}$ & 34 & 13 & $\begin{array}{l}\text { 'I think experience will make things a lot easier ... I just think that even with all the support ... } \\
\text { sometimes that's not enough. I'm looking forward to } 5 \text { years' time and going "oohh that's fine ... } \\
\text { I'm used to this".' (Transcript 1.) }\end{array}$ \\
\hline $\begin{array}{l}\text { Level of stress experienced } \\
\text { and responsibility to clients }\end{array}$ & 33 & 13 & $\begin{array}{l}\text { 'I think in this job there's a huge capacity for people to burn out quite quickly, considering the } \\
\text { interactions that we have with people and how in depth we go with some of the things that they're } \\
\text { involved in ... you're responsible for the whole context of their daily living ... everything has to be } \\
\text { taken to the courts, all the files and stuff, so you've really got to make sure you document really well } \\
\text {... so yeah I do get worried, you can't just shut the file and be yourself sometimes.' (Transcript 11.) }\end{array}$ \\
\hline Managing challenging clients & 30 & 12 & $\begin{array}{l}\text { 'The patients ... they're a big challenge because they're unpredictable, you can be their best friend } \\
\text { one day and their worst enemy the next. That's really challenging, and it's physically intimidating } \\
\text { sometimes, dealing with the patients and the nature of the environment that we're in.' (Transcript 3.) }\end{array}$ \\
\hline $\begin{array}{l}\text { Working within the culture of } \\
\text { mental health }\end{array}$ & 28 & 11 & $\begin{array}{l}\text { 'The whole procedural structure of mental health is difficult ... I think in mental health there's a } \\
\text { different culture ... with the patients you don't get that immediate gratification that you do in the } \\
\text { physical arena ... and all the industrial stuff like unions, management and political issues here ... } \\
\text { it takes a bit to get your head around quickly, and all that stuff does impact in your services.' } \\
\text { (Transcript 3.) }\end{array}$ \\
\hline $\begin{array}{l}\text { Size of caseloads and amount } \\
\text { of documentation }\end{array}$ & 24 & 11 & $\begin{array}{l}\text { 'I think one of the biggest challenges I had coming here, was the amount of documentation that } \\
\text { goes on before we see patients. Less than half my time is spent with patients.' (Transcript 3.) }\end{array}$ \\
\hline Lack of supervision and support & 22 & 8 & $\begin{array}{l}\text { 'You can have someone supervising you, but it's whether they're giving you what you need ... } \\
\text { it's hard to know what you need as a new grad.' (Transcript 12.) }\end{array}$ \\
\hline Going to work every day & 11 & 8 & $\begin{array}{l}\text { 'I think work in itself, like adjusting to working is stressful ... just that adjustment from being at uni } \\
\text { and having lots of spare time, then going to full time work.' (Transcript 13.) }\end{array}$ \\
\hline
\end{tabular}

themes within each core idea and illustrative quotes for each theme, are set out in Tables 3-5. The reader will note that each theme is assigned two quantitative scores. An unweighted score indicates the total number of transcripts in which the theme appears. The weighted score indicates the total number of instances in which each theme occurs (that is, taking into account multiple instances within one or more transcripts). These quantitative scores provide an indication of the relative importance of themes within each core idea. The themes are set out in rank order, with those having the highest weighted score at the top of the list within each core idea and those with the lowest weighted score at the bottom of the list within each core idea.

\section{Domain 1: Skills and knowledge required to work in a mental health setting}

The skills and knowledge identified by participants as being necessary to work in mental health settings fell into three broad categories (core ideas): discipline-specific skills and knowledge; knowledge and skills relevant to effective mental health practice by all mental health professionals and not just occupational therapists (described as 'generic'); and personal attributes that aid professional practice when working in mental health.

\section{Domain 2: Preparation for practice in a mental health setting}

Three major categories (core ideas) emerged in relation to preparation for practice: the skills and knowledge that the new graduate occupational therapists were well equipped with when commencing work; the skills and knowledge that the new graduates needed to develop further; and the unexpected challenges that the new graduates experienced while working in a mental health setting. The new graduates' preparation for practice in mental health is organised in Table 4. An exception to the rule was made when considering the first theme in the table, 'Skills developed on prac'. Only five participants had had a practice placement in mental health; however, as all five participants commented on its importance in preparing them to work in a mental health setting, the theme was included in the analysis.

\section{Domain 3: Achieving skills to work in mental health}

Two main categories (core ideas) emerged regarding the methods that the graduates used to develop the skills required to work as occupational therapists in a mental health setting. The typical and general themes relating to the personal coping strategies of the participants and the 
influence of the work setting in developing their skills and confidence are organised in Table 5.

\section{Discussion}

This study sought to identify the challenges that new graduates experience when commencing work in a mental health setting. The essential skills and knowledge identified by new graduates working in mental health (all the skills listed in Table 1, a digest of published descriptions of the skills required by occupational therapists working in mental health) were discussed by the participants. The challenges relating specifically to mental health practice included selecting and administering appropriately occupational therapy specific assessments; counselling (in particular, cognitive behavioural therapy and dialectical behavioural therapy); boundary setting with clients; managing high levels of stress and responsibility to clients; and maintaining a professional identity when working in a generic or case management role. Although these challenges have not previously been identified for new graduates, it has been well established that they are challenges experienced commonly in mental health by all occupational therapists (Krupa and Clark 1995, Lloyd and King 2004, Duffy and Nolan 2005).

The participants identified some challenges that have not previously been reported in the literature relating to occupational therapists working in mental health. Developing a sound knowledge of the medications used and their applications for varying diagnoses, utilising occupational therapy frameworks when developing interventions, working within the culture of mental health, and understanding the procedures associated with mental health legislation were considered areas in which the participants lacked confidence and competence. Krupa and Clark (1995) and

U: Unweighted value refers to the total number of transcripts in which the theme was mentioned.

W: Weighted value refers to the total number of instances (including multiple instances within a single transcript) of the themes across all transcripts.

Table 5. Domain 3: Achieving skills to work in mental health

\begin{tabular}{lll}
\hline Themes W U Ilustrative quotes & U \\
\hline Core idea 1: Personal coping strategies &
\end{tabular}

Seeking out mentors and networking

$47 \quad 14$

Debriefing informally with

$32 \quad 15$

colleagues

Looking after own mental health

$28 \quad 11$

Using discipline-specific skills

when possible

Work and research in own time

$26 \quad 12$

Reflecting on and learning

from mistakes

Being realistic about abilities

as a new graduate

\section{Core idea 2: Influence of the workplace}

Team cohesion and workplace

politics influenced adjustment

Performance appraisal and development plans and other workplace initiatives were beneficial
'I had no resources to start with, so I went around and found all the resources I could ... I spoke to the other OTs in the community and found out what assessments they used and how they ran their groups ... I'm planing on doing a bit more networking with other OTs in mental health, because it would be good to know what they're doing.' (Transcript 14.)

5 'All the OTs here are all really supportive of each other and just informally tell each other what's going on and get each other's opinions and that sort of thing ...' (Transcript 9.)

11 'When you start to think about clients too much, I think it's important to have an ADO every now and again. Having a day off helps you get a bit of perspective and helps you realise that you're not the only person in your clients' life.' (Transcript 13.)

1 'The breadth that we take in this [case management] role is absolutely massive, but you approach it from your OT framework ... all the OTs here get together and talk about OT stuff and make sure that we're integrating it into our mental health roles.' (Transcript 11.)

12 'There just wasn't enough time at work to fit in OT reports, so all the OT assessments I would do in work time, but then I used to do the reports at home ... just because I needed the extra time ... it also meant that I could study the assessment and the scoring and administration rules.' (Transcript 10.)

1713 'I do think about things ... like what I'm going to do the next day, and what do I need to research, and I think about ways I could do things better.' (Transcript 13.)

149 'I think you want to get involved a lot more to know what's happening and help out people ... but I think you have to be really wary of how much you take on in those first few months, because just the general day to day stuff can be overwhelming.' (Transcript 7.)

'I think it depends a lot on the team structure and the team leader ... what their philosophy is or how they run the team ... we're a very autonomous team, but at the same time our team leader is very supportive if you have any problems.' (Transcript 13.)

2812 'We have a professional development plan which I have listed the areas that I'd like to improve in and the areas that I'd like to know more about and that sort of thing ... that's a document that gets reviewed every year or more if I want to ... so supervision is fantastic and I can have structured sessions or unstructured sessions.' (Transcript 11.)

'Work's been really supportive and sending me to a lot of training ... I've been to a course nearly every week since I've been working here.' (Transcript 7.) 
Lloyd et al (2004) have suggested that there are areas in which there is a mismatch between the occupational therapy curriculum and the skills that are required to work competently in a mental health setting.

The importance of good communication and interpersonal skills was stressed. The participants talked about the need to develop confidence and assertiveness in their work. They found organisational skills, such as time management, to be a challenge. The participants felt that they had to learn to utilise stress management to improve their life balance. In addition, they found that they had to develop the ability to work autonomously and that it was important to acknowledge their own values and abilities and to be flexible.

The new graduates found that they were well equipped with the skills developed during their practice placement experience and their knowledge of occupational therapy frameworks, but that they felt that there were skills and knowledge that they needed to develop further. This, in particular, related to knowledge of the role of occupational therapy and to developing interventions based on occupational therapy frameworks. Other issues identified included areas such as client management and boundary setting, medication and diagnoses knowledge, legislation, and selecting and interpreting occupational therapy assessments. The participants experienced some unexpected challenges when commencing work. These challenges related to a lack of professional identity, working within the culture of mental health, the caseload size and the amount of documentation required, a lack of supervision and support, and the fact of the routine of going to work every day. The actual clients seen by the occupational therapists caused a degree of stress in that they were responsible for the clients and managing challenging clients was seen as a big issue.

The findings from this study show clearly that the new graduates were sensitive to the quality of their working environment, with responses highlighting the importance of working amongst a supportive team and receiving adequate supervision. The participants receiving these opportunities encountered more positive experiences in their initial employment compared with those working in poorly structured teams and receiving inadequate supervision. This was true for the new graduates working in both inpatient and community settings. Previous literature has suggested that the quality of the workplace environment is influential on both retention and withdrawal from occupational therapy practice in mental health settings (Wolfenden et al 1996, Onyett et al 1997, Hunter and Nicol 2002).

Several differences were identified when comparing the challenges that the participants experienced while working in various settings within the field of mental health. Those who were working in inpatient settings placed a greater importance on understanding mental health legislation and formal protocols within the workplace. They also discussed more frequently the necessity of being aware of the available occupational therapy assessments specific to mental health, and the associated administration and interpretation of these assessments. The new graduates working in inpatient settings frequently reported a general lack of understanding of the occupational therapist's role within the interdisciplinary team. This is consistent with the findings of Duffy and Nolan (2005). An in-depth knowledge of the medications used was not regarded as being necessary for competent practice in an inpatient setting, largely due to the availability of nursing and medical staff to whom clients directed their questions. In contrast, the participants working in the community strongly emphasised the importance of understanding medications and the diagnoses that were used in their treatment. They also more frequently discussed the challenges relating to working in a generic position, and the importance of finding ways to utilise their occupational therapy skills when working in a generic role. This supports the findings of Lloyd et al (2002).

The new graduates working in the community also reported increased feelings of responsibility for their clients and completed work in their own time more frequently than the participants working in an inpatient setting. Although acknowledging the high levels of responsibility and stress associated with their working environment as documented by Lloyd et al (2005), the new graduates working in community settings reported increased levels of workplace support and job satisfaction. This suggests that community settings can be appropriate work settings for new graduates as long as there is appropriate support, supervision and opportunities for professional development. These findings emphasise the need for supported and graded entry into the mental health workforce, and also support previous recommendations (Parker 1991, Hummell and Koelmeyer 1999).

As Lyons (1995) and Atkinson and Steward (1997) found, practice placement education experiences in the work setting were beneficial in preparing new graduates for professional practice. All five participants who had had practical experience in a mental health setting highlighted the extent to which their placements had prepared them for practice. Furthermore, the participants who had had practical experience generally reported a more positive experience of work in a mental health setting than did those who had not had such placements. It is not clear whether their positive experience was because of better preparation as a direct result of their placement, or if other factors, such as an initial positive attitude towards working in mental health, influenced this finding.

The most frequently reported strategy that the new graduates used to develop their confidence was seeking out mentors and networking with other occupational therapists. They also discussed the importance of utilising their support networks, looking after their own mental health and being realistic regarding their abilities as new graduates. The responses generally showed a commitment to the profession and professional development, with 11 out of the 15 participants reporting that they would like to do further training to improve their practice. The 
workplace was an influence on the participants and they talked about how the team and workplace politics influenced their adjustment. The use of performance appraisals and personal development were seen as being beneficial.

\section{Limitations of the study}

There are a number of limitations that must be considered when interpreting the results from this study. First, as is common in this type of research, the sample, while drawn systematically, was small and derived from a limited geographical location, meaning that the results cannot necessarily be generalised. The sample is probably representative of new graduate occupational therapists working in mental health services in south-east Queensland (although it is possible that the three eligible new graduates who declined participation may have responded differently). Also, there would have been other new graduates who were not members of OT Australia and were not included. It is not known if they would have had different views to people who were members. The sample consisted of predominantly female participants and it is not known if males would have reflected the same issues. The types of question asked related to challenges and may well have influenced the participants to respond accordingly.

\section{Implications and recommendations}

Notwithstanding the limitations discussed above, these results have implications for future research. Although the consensual qualitative research process is a recognised means of generating themes in data, it would be beneficial to confirm the reliability of the categories used in the analysis by using an external validation process. Once reliability is confirmed, the results of the study could be used as the basis for a quantitative questionnaire administered on a larger sample. It would be useful to conduct comparative studies in other locations to determine if the themes evident from this study are similar throughout Australia.

In addition to the supervision needs of new graduates, the study identified several issues that might be considered in any review of the university curriculum for occupational therapists:

1. Given the value that the participants placed on mental health practice placement education, it is recommended that mental health pracice placements be compulsory for all students. This is consistent with recommendations made by Lyons (1995) and Atkinson and Steward (1997).

2. It is recommended that the introduction of a mental health elective be considered and that the elective covers the following areas of skills and knowledge, highlighted by the participants as being areas of subject matter for which they felt inadequately prepared:

i. The occupational therapist's role in different mental health settings. To create interest and ensure competence when working in mental health settings, it is essential that new graduates leave university with a sound understanding of the occupational therapist's role in both inpatient and community mental health settings. ii. Administration and interpretation of the occupational therapy assessments available for use in mental health. As standardised assessments are a key factor in evidence-based practice, it is essential that graduating occupational therapists are equipped with increased knowledge and skills in this area.

iii. A greater emphasis on mental health legislation, with practical applications used to generate further understanding.

iv. A greater emphasis on counselling frameworks and skills in the later years of the course.

\section{Conclusion}

This study used consensual qualitative research to investigate the challenges experienced by new graduate occupational therapists working in mental health settings. The challenges identified by the new graduates included the use of discipline-specific assessments, counselling, boundary setting, and the high level of stress and responsibility that they experienced in working with clients. The new graduates also indicated that they required more information about medication, diagnostic categories and legislation. The quality of supervision and support was critical to the development of their confidence as occupational therapists. Although these findings are derived from a small sample of participants from an even smaller sample of training institutions, the consistency of themes suggests that there is scope for educational institutions to prepare students better for contemporary mental health practice.

\section{Acknowledgements}

Special thanks to Ms Rebecca Parker for her support and guidance and to the occupational therapists who took the time to participate in this research project.

This project was completed while the third author was completing her Honours degree in occupational therapy in the Division of Occupational Therapy, The University of Queensland, Australia.

\section{References}

Atkinson K, Steward B (1997) A longitudinal study of occupational therapy new practitioners in their first years of professional practice: preliminary findings. British Journal of Occupational Therapy, 60(8), 338-42.

Australian Health Ministers (1992) National mental health plan. Canberra: Australian Government Publishing Service.

Australian Health Ministers (1996) National standards for mental health services. Canberra: Australian Government Publishing Service.

Australian Health Ministers (1998) Second national mental health plan. Canberra: Australian Government Publishing Service.

Australian Health Ministers (2003) National mental health plan 2003-2008. Canberra: Australian Government.

Craik C, Austin C (2000) Educating occupational therapists for mental health practice. British Journal of Occupational Therapy, 63(7), 335-39.

Craik C, Chacksfield JD, Richards G (1998) A survey of occupational therapy practitioners in mental health. British Journal of Occupational Therapy, 61(5), 227-34. 
Duffy R, Nolan P (2005) A survey of the work of occupational therapists in inpatient mental health services. Mental Health Practice, 8(6), 36-41.

Greaves AJ, King R, Yellowlees P, Spence S, Lloyd C (2002) The competence of mental health occupational therapists. British Journal of Occupational Therapy, 65(8), 381-86.

Harries P (1998) Community mental health teams: occupational therapists' changing role. British Journal of Occupational Therapy, 61(5), 219-20.

Hill CE, Thompson BJ, Williams EN (1997) A guide to conducting consensual qualitative research. The Counseling Psychologist, 25(4), 517-72.

Hill CE, Thompson BJ, Hess SA, Knox S, Williams EN, Ladany N (2005) Consensual qualitative research: an update. The Counseling Psychologist, 52(2), 196-205.

Hummell J, Koelmeyer L (1999) New graduates: perceptions of their first occupational therapy position. British Journal of Occupational Therapy, 62(8), 351-58.

Hunter E, Nicol M (2002) Systematic review: evidence of the value of continuing professional development to enhance recruitment and retention of occupational therapists in mental health. British Journal of Occupational Therapy, 65(5), 207-15.

Krupa T, Clark C (1995) Occupational therapists as case managers: responding to current approaches to community mental health service delivery. Canadian Journal of Occupational Therapy, 62(1), 16-22.

Lee S, Mackenzie L (2003) Starting out in rural New South Wales: the experiences of new graduate occupational therapists. Australian Journal of Rural Health, 11(1), 36-43.

Lloyd C, King R (2004) Work activities of occupational therapists in Australian mental health services. International Journal of Therapy and Rehabilitation, 11(4), 154-59.

Lloyd C, King R, Bassett H (2002) A survey of Australian mental health occupational therapists. British Journal of Occupational Therapy, 65(2), 88-96.

Lloyd C, McWha L, King R (2003) An investigation of occupational therapy practice in New Zealand mental health services. New Zealand Journal of Occupational Therapy, 50(2), 9-16.

Lloyd C, King R, McKenna K (2004) Generic versus specialist clinical roles of occupational therapists and social workers in mental health. Australian and New Zealand Journal of Psychiatry, 38(3), 119-24.

Lloyd C, King R, McKenna K (2005) Sources of stress experienced by occupational therapists and social workers in mental health settings. Occupational Therapy International, 12(2), 81-94.

Lyons M (1995) Learning in context: perceived benefits of fieldwork education in community mental health settings. British Journal of Occupational Therapy, 58(6), 245-49.
Onyett S, Pillinger T, Muijen M (1997) Job satisfaction and burnout among members of community mental health teams. Journal of Mental Health, 6(1), 55-66.

Parker C (1991) The needs of newly qualified occupational therapists. British Journal of Occupational Therapy, 43(5), 164-68.

Paul S (1996) Mental health: an endangered occupational therapy specialty? American Journal of Occupational Therapy, 51(1), 65-68.

Rugg S (1999) Junior occupational therapists' continuity of employment: what influences success? Occupational Therapy International, 6(4), 277-97.

Sutton G, Griffin MA (2000) Transition from student to practitioner: the role of expectations, values and personality. British Journal of Occupational Therapy, 63(8), 380-88.

Tryssenaar J (1999) The lived experience of becoming an occupational therapist. British Journal of Occupational Therapy, 62(3), 107-12.

Tryssenaar J, Perkins J (2001) From student to therapist: exploring the first year of practice. American Journal of Occupational Therapy, 55(1), 19-27.

Wolfenden K, Blanchard P, Probst S (1996) Recruitment and retention: perceptions of rural mental health workers. Australian Journal of Rural Health, 4(2), 89-95.

Yau MK (1995) Occupational therapy in community mental health: do we have a unique role in the interdisciplinary environment? Australian Occupational Therapy Journal, 42(3), 129-32.

\section{Appendix 1. Interview questions}

1. What have been the main challenges that you have faced as a new graduate working in mental health?

2. What strategies help you cope with these challenges?

3. What knowledge do you feel is essential to have as a new graduate occupational therapist working in mental health?

4. What skills do you feel are essential to have as a new graduate occupational therapist working in mental health?

5. Describe any aspects of your employment that you feel you were inadequately prepared for in your undergraduate training.

6. Are there any particular areas of knowledge or practice skills relating to work in mental health that you feel should have been emphasised more in the university curriculum?

7. Are there any ways which you feel the workplace could improve the supervision or support given to new graduates when entering the mental health workforce?

8. Do you think occupational therapists working in mental health would benefit from a specialised postgraduate mental health training course? 